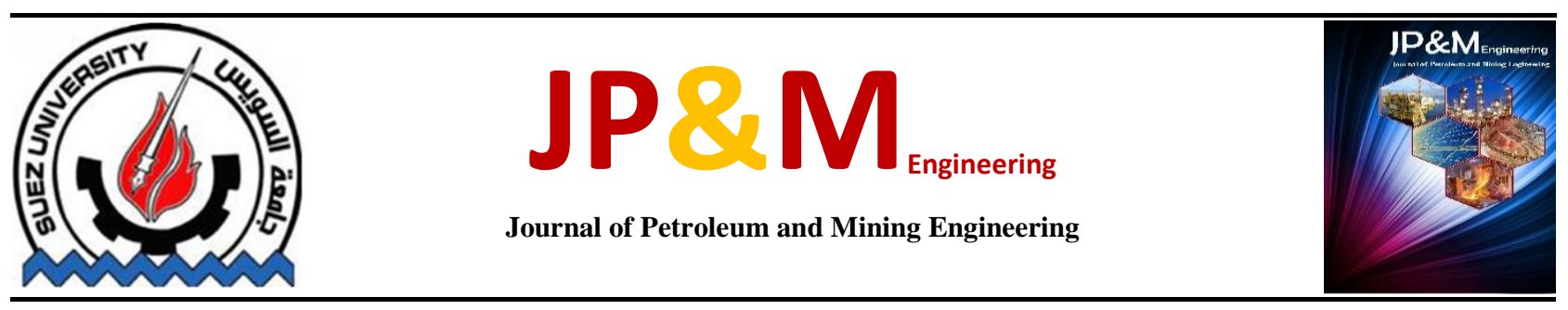

\title{
Hydrogen Distribution Network of Medor Refinery Plant by Using Two Different Optimization Techniques
}

\author{
Fatma K. Gad ${ }^{1}$, Jin K. Kim², Abeer M. Shoaib ${ }^{1}$,Walaa M. Shehata ${ }^{1}$, \\ ${ }^{1}$ Department of chemical and Refinery Engineering, Suez University, Egypt \\ ${ }^{2}$ Department of Chemical Engineering, Hanyang University, Korea
}

\section{Keywords}

$\mathrm{H}_{2}$ integration, $\mathrm{H}_{2}$ distribution network, Optimization techniques, $\mathrm{H}_{2}$ management.

\begin{abstract}
Hydrogen consumption of refineries is rising sharply with the increase of conversion units such as hydrocracking and hydrotreating processes, since these processes play an important role in modern and integrated refineries to upgrade the heavy crude oil to more valuable products. Therefore hydrogen distribution network becomes unavoidable inspite of its complexity. So the refinery hydrogen management techniques are developed in recent years to determine maximum hydrogen recovery networks which do not account for varying operating conditions of hydrogen consuming processes and assume constant operating conditions. This paper addresses the problem of actual hydrogen distribution at the Medor refinery plant at Alexandria-Egypt in which different optimization techniques were applied to minimize the consumption of hydrogen. Additionally, an efficient network design has been achieved that reduces the hydrogen utilities usage by $14.9 \%$, hydrogen discharge by $33 \%$ and

3.242 MUS\$/year saving in the operating costs.
\end{abstract}

\section{Introduction}

There are reasons for refineries to increase their use of hydrogen in recent years. The first reason is the move to heavier crud oils made refineries increase the use of hydrocracking processes as a means of upgrading heavy oils to middle distillates. Another reason is the regulations on the sulphur content of fuels made refineries increase the use of hydrotreating processes. Catalytic reforming process is considered as a major source of hydrogen for refinery industry catalytic reforming process produces amount of hydrogen as a by-product and this amount of hydrogen is affected by the need for the low aromatic gasoline. As a result, the overall availability of hydrogen in the refinery is decreased [1, 2]. Some specific technologies are applied on hydrogen network such as purification technologies to increase the amount of recycled hydrogen [3, 4]. If the amount of recycled hydrogen is increased, the amount of hydrogen that is sent to the furnaces with the off gas will decrease. As a result, the amount of fresh hydrogen obtained from hydrogen plant is decreased and can be removed from the network $[5,6]$. There are many processes in the refinery dealing with 
hydrogen if we separate these processes and hydrogen plant from other refinery processes, a refinery hydrogen network can be formed. Fig (1) [7] gives us an example of refinery hydrogen network with two hydrogen producers and six hydrogen consumers. In this hydrogen network, the two main hydrogen producers are the catalytic reforming and hydrogen plant. Catalytic reforming increases the octane number of heavy naphtha by cyclization and dehydrogenation of aliphatic hydrocarbon molecules into aromatic compounds and at the same time generates large amounts of hydrogen at $70-90 \%$ purity as a by-product [8]. The second hydrogen producer is the hydrogen plant which produces hydrogen with purity of exceeding 99\% [8,9]. The hydrogen consumers are hydrocracker (HCU), diesel hydrotreater (DHU), kerosene hydrotreater (KHU), cracked naphtha hydrotreater (CNHU), naphtha hydrotreater (NHU), and hydrodealkylation (HDA). After hydrogen consumption, the purge gas will be sent from hydrogen consumers outlets to the fuel system. In this paper, the application of a mass integration procedure techniques hydrogen appropriate purifier from pressure swing adsorption processes (PSA), and membranes for recovering hydrogen from refinery off-gases is applied to minimize the hydrogen utility.

\section{Literature Review}

Hydrogen management was considered to be important in both design and operation. Simpson 1984 [9] proposed the work over hydrogen management that is based on the analysis of the hydrocarbon thermodynamic. Appropriate operating conditions and strategy of using catalyst are two main factors of

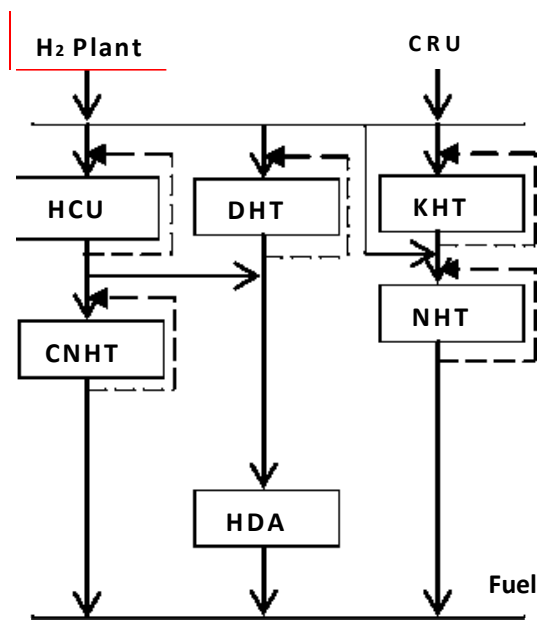

Figure 1 A typical hydrogen network.

Towler et al., 1996 [10] developed the first systematic approach for hydrogen management. Economics analysis of hydrogen recovery against added values in product by hydrogen is proposed as the main feature in this method. Hydrogen is recovered for a cost and brings extra value to fuel products. When the extra value brought by hydrogen can not compensate the cost of hydrogen recovery, it is not preferred to recover hydrogen because no profit can be made. Under this concept, the cost and value composite curves can be plotted for either hydrogen producers or consumers. The value added to products can be calculated as the value of products minus the summation of the value of feedstock, operating cost and capital cost. The cost of hydrogen recovery is represented by the cost of hydrogen purification units. The proposed methodology can be used not only for an economic analysis of a refinery hydrogen network, but also for refinery operation management, sensitivity analysis and in 
examining retrofit design options. However, the essential economic data to the analysis such as the added value by adding hydrogen will not be always available for refineries, bringing difficulties in applying the method. Another limitation of this method is the lack of hydrogen purifier selection and placement strategies. Linnhoff et al., 1979 [11] proposed the pinch technology for heat exchanger network synthesis. By plotting cold streams and hot streams data into a composite curve, the overall heat exchanger network's pinch point can be found leading a theoretical optimal solution. Alves, 1999 [6] utilized Linnhoff's work and extended the pinch technology into the hydrogen network field. Hydrogen sinks and sources are introduced similarly to the cold and hot exchanger networks. With observation on the balance between hydrogen sinks and sources, hydrogen pinch analysis gives a general overview of the hydrogen usage situation of a specific $_{\text {Liqui }}$ hydrogen network. In order to apply the pinchfeed technology on hydrogen networks, hydrogen sources and sinks must be defined in a simplified hydrogen consumer model [6].

Fig (2) shows a simplified hydrogen consumer model. The figure illustrates how hydrogen flows and is used through a process. The hydrogen sink, located at the inlet of the consumer, is defined as the mix of the makeup hydrogen and the recycle stream. The make-up hydrogen mainly comes from a $\mathrm{H} 2$ plant or a catalytic reformer. Fsink and Ysink are used to denote the flow rate and purity of a sink. On the other hand, a hydrogen source locates at the outlet of a hydrogen consumer, containing a purge stream and a recycle stream. A hydrogen source is a hydrogen-rich stream that can be utilized by hydrogen consumers. It can be off-gas from other hydrogen consumers. In the hydrogen consumer model the hydrogen source would be the mixture of purge and recycle stream. Fsource and Ysource are used to denote the flow rate and purity of a source. Fig (2) also demonstrates how a hydrogen consumer unit works. Make-up hydrogen will be mixed with liquid hydrocarbon feed. The mixture is then sent into a reactor for reaction under certain operating conditions. The after reaction stream goes into the flash separation unit and gets stripped into vapour and liquid. The vapour phase portion can be recycled or purge, while the liquid phase becomes a fuel product afterwards.

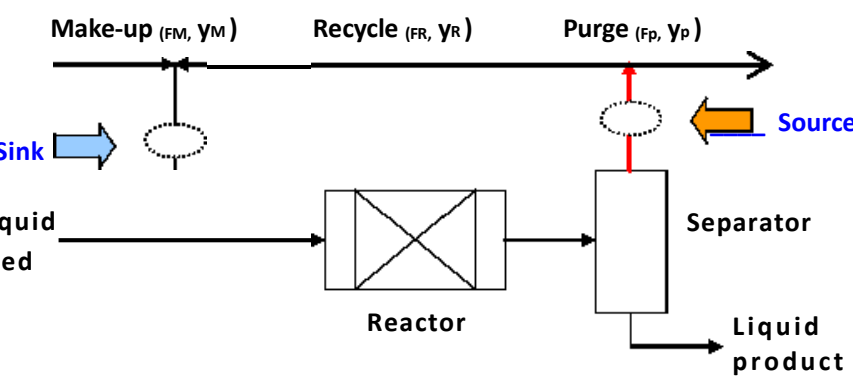

Figure 2. Simplified representation of a hydrogen consuming process in hydrogen pinch analysis [13].

Alves, 1999 [6] proposed a linear programming (LP) approach for optimizing $\mathrm{H}_{2}$ network. Hallale et al., 2001 [1] and Liu, 2002 [12] developed the methodology of automated hydrogen network design using a mixed integer non-linear programming (MINLP) method. Liu has taken the pressure into consideration as well as the hydrogen purifier placement strategy. El Halwagi, 2003 [18] proposed a mathematical linear program for optimizing $\mathrm{H}_{2}$ network. Ahmed, 2011 [7] extended the problem formulation to address the multi-period problem faced by $\mathrm{H}_{2}$ network. All these design methods have a 
common feature of representing a hydrogen network design problem as a superstructure, and then use mathematical programming algorithms to obtain optimal solutions.

\section{Hydrogen purification methods}

There are three hydrogen purification methods, pressure swing adsorption (PSA), membranes, and cryogenic units. Selecting the mostappropriate hydrogen purification technology, depends upon both procedural requirements (hydrogen recovery, feed, and product) and operational requirements (flexibility, reliability, feed pre-treatment, and by- product recovery) $[13,14,15]$.

(I) Pressure swing adsorption (PSA) units are well suited for purifying catalytic reformer hydrogen used in hydroprocessing units. Feed purity of the PSA units is up to $40 \mathrm{vol}$. \%. PSA units produce hydrogen with recovery up to 90 $\%$ and with 99.9 vol. \% purity.

(II) Membrane units are suited for recovering hydrogen from high pressure purge gases. Membrane is used when the feed purity is up to $25 \mathrm{vol}$. \%. The hydrogen product is with recovery up to $95 \%$ and with 98 vol. \% purity.

(III) Cryogenic units used when the hydrogen content of the feed is 15-80 vol. \%. Cryogenic units require feed pretreatment and give by-products such as methane and ethane. In the cryogenic units, the hydrogen product is with recovery up to $98 \%$ and 97 vol. \% purity [12].

By adding a purifier to the hydrogen network, a new sink (the feed stream) and two new sources (product and residue streams) have been actually added to the network. Fig (3) shows a schematic diagram of the purifier. Mass balance around the purifier gives:

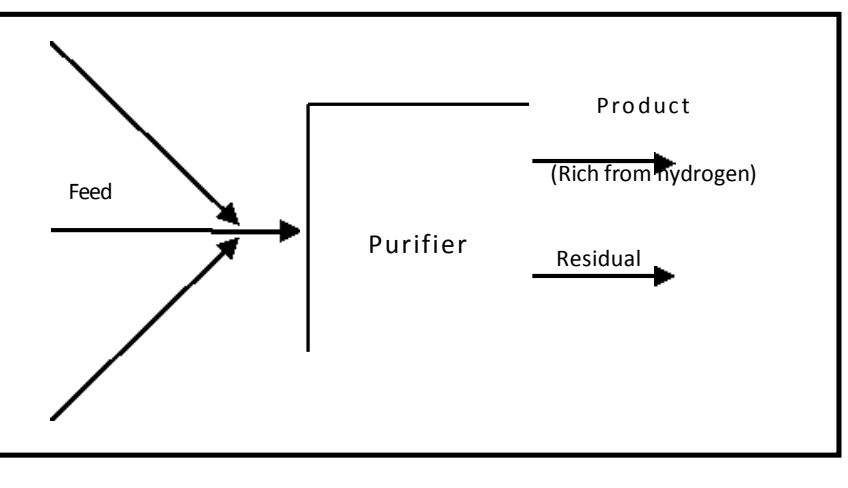

Figure 3. Schematic diagram of purifier [12]

- Viscous

- fluids Foam

$$
\begin{aligned}
\sum_{i} F_{i, p u r}=\sum_{j} & F_{\text {prod }, j} \\
& +F_{\text {residual }}
\end{aligned}
$$

Hydrogen balance around the purifier gives:

$$
\begin{gathered}
y_{\text {prod }} * \sum_{j} F_{\text {prod }, j}=R * \sum_{i} F_{i, p u r} \\
* y_{i}
\end{gathered}
$$

The low-impurity product stream can either be reused in another hydrogen consuming process or recycled to the same process. A high-impurity by-product stream is either purged or used as fuel. The works applied in this paper are:

(i) Study and apply the cascade analysis technique.

(ii) Study and apply mathematical programming technique.

(iii)Apply the two techniques to industrial case study of Medore refinery plant at Alexandria-Egypt.

(iv) Study two different purification units, membrane and pressure swing adsorption (PSA).

(v) Comparison between the costs of the hydrogen network of Medore refinery plant with the two purification units. 


\section{Cascade analysis technique}

The first step in conducting the cascade technique is to locate the various sinks and sources at their respective concentration levels. As shown in Table 4, the concentration levels $\left(\mathrm{C}_{\mathrm{k}}\right)$ are arranged in an ascending order and the flow rate of each sink $\left(\mathrm{F}_{\mathrm{j}}\right)$ and source $\left(\mathrm{F}_{\mathrm{i}}\right)$ is located individually at its respective concentration level $\mathrm{k}$ in columns 3 and 4. Column 5 is the net flow rate $\sum_{\mathrm{i} F i}-\sum_{\mathrm{j}} \mathrm{Fj}$ between sources and sinks at each concentration level k; positive values indicate a surplus, negative values indicate a deficit [16]. The next step is to cascade the net flow rate surplus/deficit down the concentration levels to yield the cumulative surplus/deficit flow rate $\left(F_{C}\right)$ shown in column 6 of Table 4 and, the overall net surplus/deficit for the network. A zero fresh flow rate is assumed at this stage to facilitate the search for the minimum utility gas flow rate. The two final steps in getting the minimum utility targets involve setting up the cumulative impurity load cascade (cum $\Delta \mathrm{m}$, column 8), and finally calculating the flow rate of fresh hydrogen needed at each concentration level, or the interval fresh gas flow rate, $(\mathrm{FF}, \mathrm{k})$. The largest negative $F F, k$, which actually represents the minimum fresh gas target that cascaded down the cumulative gas flow rate column $(\mathrm{FC})$, yields the minimum discharge flow rate. The impurity load $(\Delta \mathrm{m})$ shown in Column 7 of Table 4 is obtained from the product of cumulative flow rate $\left(\mathrm{FC}_{\mathrm{C}}\right)$ and the concentration difference across two concentration levels $(\Delta \mathrm{C})$.

$\Delta m=F C * \Delta C / 1000$

Cascading the impurity load down the concentration levels of column 8 yields the cumulative load (cum $\Delta \mathrm{m}$ ). The amount of interval fresh gas flow rate $(\mathrm{FF}, \mathrm{k})$ is obtained by dividing cum $\Delta \mathrm{m}$ by the difference between the concentration at level $\mathrm{k}\left(\mathrm{C}_{\mathrm{k}}\right)$ and the fresh feed concentration $(\mathrm{CF})$.

$$
F_{F, K}=\frac{\operatorname{cum} \Delta m * 1000}{C_{k}-C_{F}}
$$

The absolute value of the largest negative $(\mathrm{FF}, \mathrm{k})$ is the minimum fresh gas flow rate target $(\mathrm{FF})$. This amount is cascaded down the $\mathrm{FC}_{\mathrm{C}}$ column of the feasible cascade as described in Table 5, to produce the minimum discharge flow rates $(\mathrm{FD})$ [16]. The changes in the cascade tables in case of adding a purifier is the location of the flow rate of fresh hydrogen FF as described in the cascade technique in the reference [16]. FF is located in the column 5 instead of column 6 at its concentration as described in Table 6 and Table7. Also the feed flow at the pinch point is decreased by the amount of the discharge flow rate which purified by the purifier. In the cascade technique, the hydrogen network is divided into two design regions above the pinch and below the pinch. Above the pinch region, the fresh hydrogen is used and no fuel generation. In each interval above the pinch, the sink takes its requirements from the source in that interval. Fresh hydrogen is added to any sink in any interval if the source flow rate is less than the sink flow rate in that interval and there is not any source residual from the above intervals. Below the pinch region, there is not fresh hydrogen to be used and only fuel is generated. Each sink in any interval below the pinch takes its requirements from the source in that interval. If the source flow rate in any interval is less than the sink flow rate in that interval, any source residual from the above intervals must be added to the sink. The unused source residual from each interval is discharged as a fuel [19].

\section{Mathematical Programming Technique}

A source-sink representation as described in Figure 4 is the first step in the application of the mathematical technique. Each source is split into fractions (of unknown flow rate) that are allocated to the various sinks. A waste sink is an additional sink placed to account for unrecycled / unreused material. Also, the fresh resource is allowed to split and is allocated to all process sinks except the waste sink $[17,18]$. 


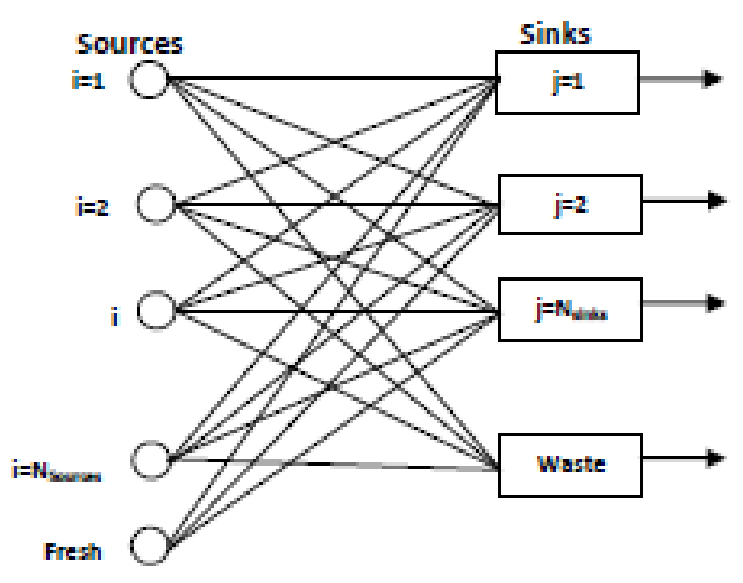

Figure 4. Source/ Sink allocation [18].

The objective function is to minimize the consumption of fresh resources.

\section{Minimize consumption of fresh resource$$
=\sum_{j=1}^{n_{\text {sinks }}} F_{j}
$$

Each source i, is split into Nsinks fractions as described in fig (5). The flow rate of each split is $\mathrm{j}$. Also, one split is forwarded to the waste sink which is denoted by wi,waste [18].

$$
w_{i}=\sum_{j=1}^{N_{\text {anink }}} w_{L,}+w_{\text {Lweste }} \text { for } i=1,2,3, \ldots, N_{\text {source }}
$$

The following step is the mixing of the split fractions into a feed to the jth sink as described in Figure 6. The split fractions come from the process sources and the fresh stream [18].

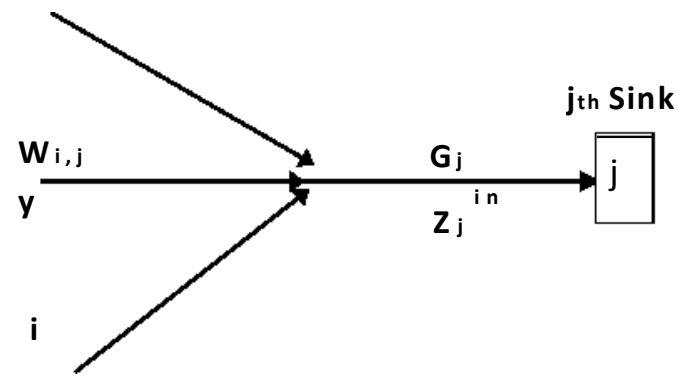

Figure 6. Mixing of Sources at inlets of Sinks [18].
$G_{j}=F_{j}+\sum_{t=1} w_{L, j} \quad$ for $j=1,2,3, \ldots, N_{\text {sinde }}$

$G_{j} z_{j}^{\text {in }}=\sum_{i=1}^{\text {Nenearas }} w_{i, j} y_{i} \quad$ for $j=1,2,3, \ldots, N_{\text {sink }}$

Where:

$z_{j}^{\min } \leq z_{j}^{j^{n}} \leq z^{\max } \quad$ for $j=1,2,3, \ldots, N_{\text {sinks }}$

To ensure the non-negativity of the fresh flows and the fractions of sources allocated to a sink, the following constraints are applied:

$$
\begin{gathered}
w_{i, j} \geq 0 \quad \text { for } i=1,2,3, \ldots, N_{\text {sources }} \text { and } j \\
=1,2,3, \ldots, N_{\text {sinks }} \\
F_{j} \geq 0 \quad \text { for } j=1,2,3, \ldots, N_{\text {sinks }}
\end{gathered}
$$

The above formulations are a linear program that can be solved to obtain the optimal target and source-sink matches [18]. In this work Lingo program v.13 is used. By applying the mathematical technique, The network design is obtained through the program. The total annual cost is calculated for all cases, existing $\mathrm{H}_{2}$ network, integrating $\mathrm{H}_{2}$ network by mathematical or cascade technique, integrating $\mathrm{H}_{2}$ network with adding a Membrane unit, and integrating $\mathrm{H}_{2}$ network with adding a PSA unit. The total annual cost is the summation of the annual operating costs and annualized capital costs for new equipments.

$$
\begin{gathered}
T A C= \\
\text { Cost }_{\text {operating }}+A f\left(\text { Cost }_{\text {equipment }}\right)
\end{gathered}
$$

\section{Operating costs}

Operating costs are the operating costs of hydrogen production, the operating costs of electricity of the compressors, and the operating costs of the fuel value.

$$
\begin{gathered}
\text { Cost }{ }_{\text {operating }}=O C_{N 2}+O C_{E L C}-O C_{\text {Puei }} \\
O C_{H 2}=O C H+F H P
\end{gathered}
$$

$\mathrm{OCH}_{2}$ is the hydrogen production operating cost which is function of the FHP, hydrogen plant flow rate, multiplied by the unit cost of production, $\mathrm{OCH}$.

$$
O C_{E L C}=O C E\left(\sum_{K} P w r_{k}\right)
$$


OCELC is the electricity operating cost, which is a function of the Pwr, compressor's power, multiplied by the unit cost of electricity, OCE.

$$
\text { Power }=160.376\left[\left(\frac{P_{\text {out }}}{P_{\text {bn }}}\right)^{0.1 a s 7}-1\right] F_{\text {in }}
$$

- Power calculated from equation (16) is in $\mathrm{KW}$, and the flow rate into the compressor (Fin) is in MMSCFD. Discharge (Pout) and suction pressure (Pin) of compressor are in psi. Fuel gas is assumed to be a binary mixture of hydrogen and methane and both are functions of the fuel gas flow rate and the purity [20].

$O C_{\text {Pual }}=O C F+F_{\text {Fad }} \cdot\left(L H V_{N 2}+Y_{M 2}+L H V_{C H 4}+Y_{C H 4}\right)$

- OCFuel is the fuel gas value operating cost, which is function of the summation of fuel gas heating value LHV for hydrogen and methane multiplied by unit heat cost of fuel, OCF.

\section{Equipment Cost}

Equipment costs are the cost of the PSA or membrane purifier added to the $\mathrm{H} 2$ network. The cost of a PSA unit has been correlated as a simple linear function of the feed flow rate [20].

$\operatorname{Cap}_{P S A}=a_{P S A}+b_{P S A}+F_{i n}$

- CapPSA is the capital cost of the PSA unit, which is in $* 10^{3} \$$. The capital cost coefficients aPSA and bPSA are constants as 503.8 and 347.4, respectively and the PSA feed flow rate, Fin is measured in MMSCFD. - Membrane costs are more complex to estimate as those that depend on product purity as well as the membrane pressure drop. Ratan, 1994 [21] provides some data [1].

-Af means annualizing factor, and is addresses

$$
\text { as: } \quad A f=\frac{f+(1+h)}{\left(1+h_{1}\right)^{y}=1}
$$

Where fi is the fractional interest and ny is the number of years.

\section{Case study}

This case study is representative of a real refinery system. Fig (7) shows the existing hydrogen network in the Medor Refinery Plant at Alexandria-Egypt. There are four consuming units, naphtha hydrotreating, isomerisation, diesel hydrotreating, and hydrocracking unit. The hydrogen is supplied by catalytic reforming unit and hydrogen plant. All the consuming units have recycle compressors except the isomerization unit. Currently $2263.67 \mathrm{kmole} / \mathrm{hr}$ hydrogen is produced from hydrogen plant. The data related to the flow rate and purity is represented in Table 1. PSA unit is used to purify some amount of hydrogen flow rate from the catalytic reforming unit and produced purified hydrogen with $99.9 \%$ purity. All purified hydrogen from PSA unit mixed with the hydrogen produced from hydrogen plant and sent to the hydrocracking unit. Table 2 represents the sink streams and the source streams of the existing network in the refinery. 


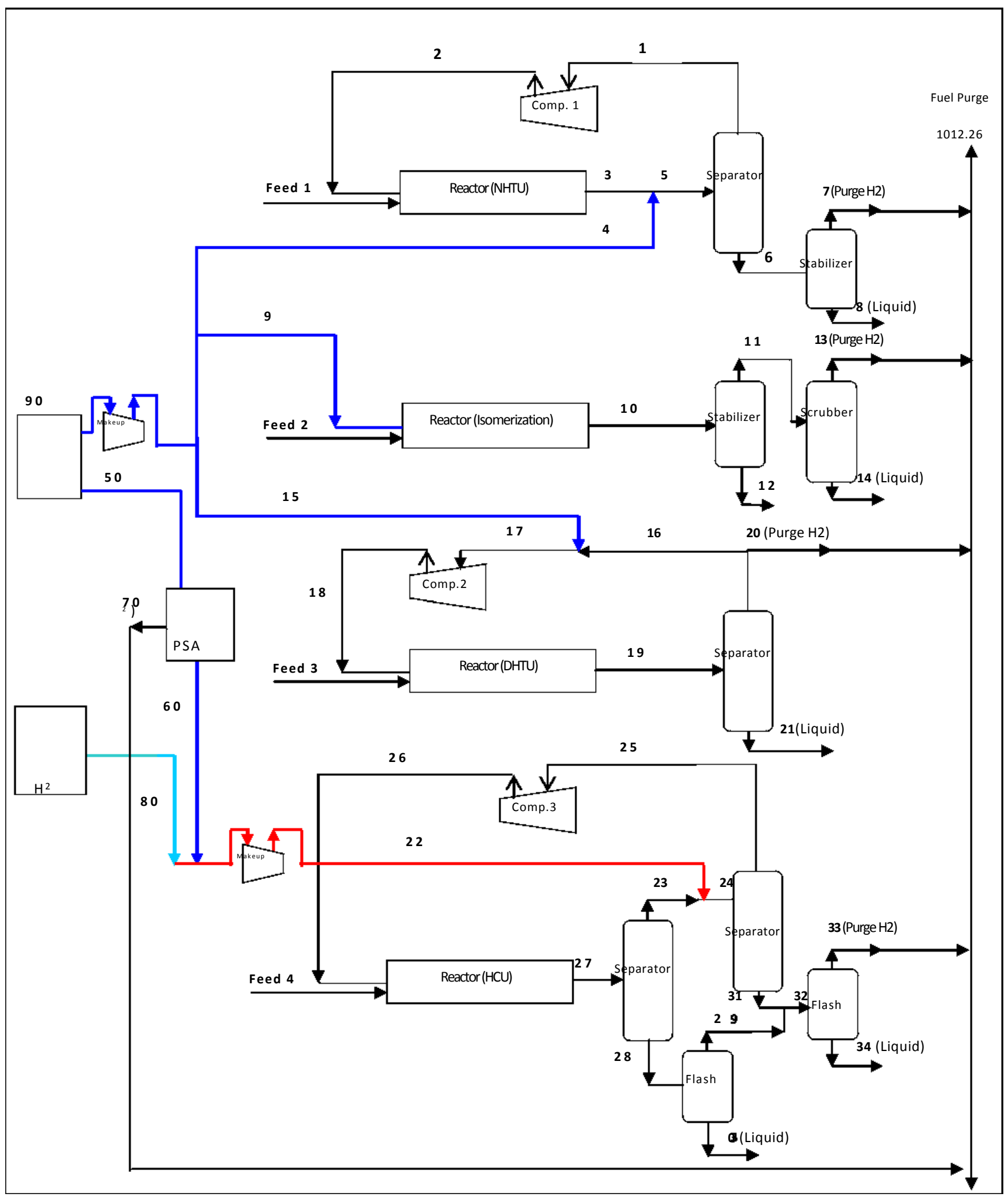

Figure 7. The Existing Network in the Case Study. 
Table 1: Streams data for the $\mathrm{H}_{2}$ network in the case study.

\begin{tabular}{|c|c|c|c|c|}
\hline $\begin{array}{c}\text { Stream } \\
\text { No. }\end{array}$ & $\begin{array}{l}\text { Flow Rate } \\
\text { (Kg mole/hr) }\end{array}$ & $\begin{array}{l}\mathrm{H}_{2} \text { Purity } \\
\text { (Mole \%) }\end{array}$ & $\begin{array}{c}\text { Pressure } \\
\text { bar }\end{array}$ & $\begin{array}{c}\text { Temp. } \\
\text { C }^{\circ}\end{array}$ \\
\hline 1 & 2024.99 & 95.62 & 41.4 & 55.0 \\
\hline 2 & 2024.99 & 95.62 & 52.4 & 77.0 \\
\hline 3 & 3472.2 & 53.56 & 45.0 & 343.0 \\
\hline 4 & 135.56 & 90.21 & 44.8 & 38.0 \\
\hline 5 & 3607.76 & 54.94 & 42.1 & 134.0 \\
\hline 7 & 97.9 & 46.84 & 7.0 & 48.0 \\
\hline 9 & 241.3 & 90.22 & 44.8 & 38.0 \\
\hline 10 & 1120.37 & 4.57 & 15.38 & 124.0 \\
\hline 11 & 121.96 & 41.99 & 7.58 & 35.0 \\
\hline 13 & 122.6 & 41.78 & 4.50 & 36.0 \\
\hline 15 & 476.54 & 90.22 & 44.8 & 38.0 \\
\hline 16 & 2396.94 & 83.04 & 34.5 & 52.0 \\
\hline 17 & 2873.48 & 84.23 & 34.5 & 50.0 \\
\hline 18 & 2873.48 & 84.23 & 50.5 & 84.0 \\
\hline 20 & Zero & Zero & Zero & Zero \\
\hline 22 & 3276.9 & 99.9 & 166.03 & 123.0 \\
\hline 23 & 20088.76 & 83.86 & 164.99 & 198.0 \\
\hline 24 & 23365.66 & 86.11 & 164.99 & 157.0 \\
\hline 25 & 22434.72 & 89.21 & 164.65 & 60.0 \\
\hline 26 & 22434.72 & 89.21 & 187.79 & 76.0 \\
\hline 33 & 515.15 & 73.48 & 31.03 & 56.0 \\
\hline 50 & 1287.8 & 90.164 & 22.0 & 38.0 \\
\hline 60 & 1011.19 & 99.9 & 20.0 & 38.0 \\
\hline 70 & 276.61 & 54.57 & 2.0 & 38.0 \\
\hline 80 & 2263.67 & 99.99 & 20.0 & 38.0 \\
\hline 90 & 2141.2 & 90.141 & 22.0 & 38.0 \\
\hline
\end{tabular}


Table 2: Sinks and Sources streams in the case study.

\begin{tabular}{|c|c|c|c|}
\hline $\begin{array}{l}\text { Sink } \\
\text { Stream } \\
\text { s }\end{array}$ & $\begin{array}{c}\text { Flow Rate } \\
\text { (kgmole/hr) }\end{array}$ & $\begin{array}{l}\mathrm{H}_{2} \text { Purity } \\
\text { (Mole \%) }\end{array}$ & $\begin{array}{l}\text { Impurity } \\
\text { (Mole \%) }\end{array}$ \\
\hline 2(NHT) & 2024.99 & 95.62 & 4.38 \\
\hline $4(\mathrm{NHT})$ & 135.56 & 90.22 & 9.78 \\
\hline 9(ISO.) & 241.3 & 90.22 & 9.78 \\
\hline 18(DHT) & 2873.48 & 84.23 & 15.77 \\
\hline $22(\mathrm{HC})$ & 3276.9 & 99.9 & 0.1 \\
\hline $26(\mathrm{HC})$ & 22434.72 & 89.21 & 10.79 \\
\hline 50(PSA) & 1287.8 & 90.164 & 9.836 \\
\hline Source Streams & $\begin{array}{c}\text { Flow Rate } \\
\text { (kgmole/hr) }\end{array}$ & $\begin{array}{l}\mathrm{H}_{2} \text { Purity } \\
\text { (Mole \%) }\end{array}$ & $\begin{array}{l}\text { Impurity } \\
\text { (Mole \%) }\end{array}$ \\
\hline 1(NHT) & 2024.99 & 95.62 & 4.38 \\
\hline 7(NHT) & 97.9 & 46.84 & 53.16 \\
\hline 13(ISO.) & 122.6 & 41.78 & 58.22 \\
\hline 16(DHT) & 2396.94 & 83.04 & 16.96 \\
\hline $25(\mathrm{HC})$ & 22434.72 & 89.21 & 10.79 \\
\hline 33(HC) & 515.15 & 73.48 & 26.52 \\
\hline 60(PSA) & 1011.19 & 99.9 & 0.1 \\
\hline 70(PSA) & 276.61 & 54.57 & 45.43 \\
\hline 90(CRU) & 2141.2 & 90.186 & 9.814 \\
\hline $\begin{array}{l}80 \text { (H2 Plant) to be } \\
\text { determined }\end{array}$ & 2263.67 & 99.99 & 0.01 \\
\hline
\end{tabular}




\section{Results and Discussion}

\section{Integration of $\mathrm{H} 2$ network}

The two techniques have been applied on the integration of Medore hydrogen network and the results showed that:

a. By applying the cascade technique as described in Table 3 and Table 4, it is found that the minimum hydrogen utility would be $2257.9641 \mathrm{kmole} / \mathrm{hr}$ instead of $2263.67 \mathrm{kgmole} / \mathrm{hr}$ and the minimum discharge would be $1004.5141 \mathrm{kgmole} / \mathrm{hr}$ instead of 1012.26. Fig (8) shows the optimum design procedure without adding any new equipment to the network. Dotted lines illustrate the new connections.

b. By applying the mathematical technique on the Medor hydrogen network by using lingo program v13 it is found that the minimum hydrogen utility would be $2257.964 \mathrm{kmole} / \mathrm{hr}$ instead of 2263.67 $\mathrm{kgmole} / \mathrm{hr}$ and the minimum discharge would be $1004.514 \mathrm{kgmole} / \mathrm{hr}$ instead of $1012.26 \mathrm{kgmole} / \mathrm{hr}$. Fig (9) shows the optimum design procedure without adding any new equipment to the network. Dotted lines illustrate the new connections.

\section{Adding a purifier}

For more recovery of hydrogen from off gases, two purification units have been added to the hydrogen network. Membrane and PSA.

\section{Adding a membrane to the $\mathrm{H} 2$ network}

Given a gas separation membrane with a hydrogen recovery of $95 \%$ [1], one possible option is to purify the portion of stream (DHT) that lies at 16.96\%. 1004.5141 $\mathrm{kgmole} / \mathrm{hr}$ is purified to a product stream at $2 \%$ impurity. From material balance calculations, the flow rate of this high quality permeate stream is $808.61 \mathrm{kgmole} / \mathrm{hr}$. The flow rate and impurity concentration for the retentate stream are $195.9 \mathrm{kgmole} / \mathrm{hr}$ and $78.71 \%$, respectively. Adding these two new hydrogen sources at their respective concentration levels yields a new cascade table shown in Table 5. From this table, the fresh hydrogen flow rate is reduced to $2163.216 \mathrm{kmole} / \mathrm{hr}$, which corresponds to a reduced discharge flow rate of 909.756 $\mathrm{kmole} / \mathrm{hr}$. The saving in fresh hydrogen is $4.44 \%$ and the discharge is reduced by $9.43 \%$. When applied the mathematical technique on the hydrogen network with adding a membrane to the hydrogen network, it is found that the fresh hydrogen flow rate is 2163.241 Kmole/hr and the hydrogen discharge is $909.791 \mathrm{kmole} / \mathrm{hr}$.

\section{Adding a PSA to the $\mathrm{H} 2$ network}

When another hydrogen purifier is used, a PSA unit with a hydrogen-recovery value of 90\% and capability to purify the hydrogen stream up to $0.10 \%$ impurity [1]. From material balance calculations, the product and residue flow rates of $751.49 \mathrm{kmole} / \mathrm{hr}$ and $253.03 \mathrm{kmole} / \mathrm{hr}$, respectively are obtained, with the residue stream impurity concentration at $67.03 \%$. Resetting targets using the cascade technique gave a reduced fresh hydrogen flow rates of $1926.35 \mathrm{kmol} / \mathrm{hr}$, which corresponds to a reduced discharge flow rate of 672.91 $\mathrm{kmol} / \mathrm{hr}$ as shown in Table 6 . The saving in fresh hydrogen is $14.9 \%$ and the discharge is reduced by $33.0 \%$. Fig (10) shows the optimum design procedure for the Medor hydrogen network with adding the new PSA unit as a purifier. When applied the mathematical technique on the hydrogen network with adding a PSA, it is found that the fresh hydrogen is $1926.356 \mathrm{kmole} / \mathrm{hr}$ and the hydrogen discharge is $672.946 \mathrm{kmole} / \mathrm{hr}$. Figure 11 shows the optimum design procedure for the Medor hydrogen network with adding the new PSA unit. 


\section{Cost Calculation Results}

The utility prices used are hydrogen 2000 US\$/MSCF (0.075 US\$/Nm3), power 0.03 $\mathrm{US} \$ / \mathrm{KWh}$, and fuel gas $2.5 \mathrm{US} \$ / \mathrm{MBTU}$ (8.53 US\$/MWh) [20]. The results of cost calculation are showed in Table 7. As described in Table 7, it is noted that: The power costs for all cases are the same and that because the flow rates entering the compressors in all cases are the same but the sources of these amounts are different. In case of integration 112 network by cascade or mathematical technique, it is found that the operating cost saving is $26000 \mathrm{US} \$ / \mathrm{yr}$. The saving in the operating cost is low that because the minimum fresh hydrogen obtained by the integration of 112 network was decreased by $5.706 \mathrm{kmole} / \mathrm{hr}$ than the actual fresh hydrogen used without integration of the 112 network. Also, the hydrogen discharge was decreased by $7.746 \mathrm{kmole} / \mathrm{hr}$ than the actual hydrogen discharge. In case of integration 112 network by cascade or mathematical technique with adding a membrane unit, it is found that the operating cost saving is 1.246 MUS\$/yr. The saving in the operating cost is increased that because the minimum fresh hydrogen obtained by the integration of 112 network with adding a membrane unit was decreased by 100.454 $\mathrm{kmole} / \mathrm{hr}$ by cascade technique or 100.429 $\mathrm{kmole} / \mathrm{hr}$ by mathematical technique than the actual fresh hydrogen used without integration of the 112 network. Also, the hydrogen discharge was decreased by $102.504 \mathrm{kmole} / \mathrm{hr}$ by cascade technique or $102.469 \mathrm{kmole} / \mathrm{hr}$ by mathematical technique than the actual hydrogen discharge In case of integration 112 network by cascade or mathematical technique with adding a PSA unit, it is found that the operating cost saving is $3.242 \mathrm{MUS} \$ / \mathrm{yr}$. The saving in the operating cost is increased than the previous cases that because the minimum fresh hydrogen obtained by the integration of 112 network with adding a PSA unit was decreased by $337.32 \mathrm{kmole} / \mathrm{hr}$ by cascade technique or $337.314 \mathrm{kmole} / \mathrm{hr}$ by mathematical technique than the actual fresh hydrogen used without integration of the 112 network. Also, the hydrogen discharge was decreased by $339.35 \mathrm{kmole} / \mathrm{hr}$ by cascade technique or $339.314 \mathrm{kmole} / \mathrm{hr}$ by mathematical technique than the actual hydrogen discharge. The PSA purifier plays a more important role in reducing the fresh hydrogen target in the hydrogen network of Medore refinery plant, compared to the gasseparation membrane. This is because a PSA generates an additional amount of purified hydrogen with higher hydrogen purity which leads to minimization of the hydrogen utilities usage by $14.9 \%$ and hydrogen discharge by 33.0\%. Also 3.242 MUS\$/year saving in the operating costs achieved by using the PSA purifier. 
Table 3: Infeasible Cascade Table for the hydrogen network in the case study (Hydrogen Integration).

\begin{tabular}{|c|c|c|c|c|c|c|c|c|}
\hline Level & $\begin{array}{l}\text { Concentration } \\
\text { Mole } \%\end{array}$ & $\begin{array}{c}F_{\text {sources }} \\
\mathrm{Kmale} / \mathrm{hr}\end{array}$ & $\begin{array}{c}\mathrm{F}_{\text {sinks }} \\
\mathrm{Kmole} / \mathrm{hr}\end{array}$ & $\begin{array}{l}\sum_{\mathrm{i}} \mathrm{F}_{\mathrm{i}}-\sum_{\mathrm{j}} \mathrm{F}_{\mathrm{j}} \\
\mathrm{K} \text { mole/hr }\end{array}$ & $\begin{array}{c}\mathrm{F}_{\mathrm{C}} \\
\mathrm{Kmole} / \mathrm{hr}\end{array}$ & $\underset{\mathrm{Kmole} / \mathrm{hr}}{\Delta \mathrm{n}}$ & $\begin{array}{l}\text { Cum } \Delta \mathrm{m} \\
\mathrm{Kmale} / \mathrm{hr}\end{array}$ & $\begin{array}{c}F_{F, k} \\
\text { Kmale/hr }\end{array}$ \\
\hline 1 & 0.01 & 0.0 & 0.0 & 0.0 & 0.0 & & & \\
\hline 2 & 0.1 & 1011.19 & 3276.9 & -2265.71 & -2265.71 & -9.6972 & 0.0 & \\
\hline 3 & 4.38 & 2024.99 & 2024.99 & 0.0 & -2265.71 & $-12,2348$ & -9.6972 & -2219.0481 \\
\hline 4 & 9.78 & 0.0 & 376.86 & -376.86 & -2642.57 & -0.0898 & -21.9321 & -2244.8380 \\
\hline 5 & 9.814 & 2141.20 & 0.0 & 2141.20 & -501.37 & -0.0110 & -22.0219 & -2246.2178 \\
\hline 6 & 9.836 & 0.0 & 1287.8 & -1287.8 & -1789.17 & -1.7069 & -22.0329 & -2242.3112 \\
\hline 7 & 10.79 & 22434.72 & 22434.72 & 0.0 & -1789.17 & -8.9101 & -23.7398 & $-2202,2096$ \\
\hline 8 & 15.77 & 0.0 & 2873.48 & -2873.48 & -4662.65 & -5.5486 & 32.6498 & -2071.6935 \\
\hline 9 & 16.96 & 2396.94 & 0.0 & 2396.94 & -2265.71 & $\begin{array}{c}-21,6602 \\
- \\
\end{array}$ & -38.1984 & -2253.5953 \\
\hline 10 & 26.52 & 515.15 & 0.0 & 515.15 & -1750.56 & -33.1031 & -59.8586 & -2257.9641 \\
\hline
\end{tabular}

Table 4:. Feasible Cascade Table for the hydrogen network in the case study.

\begin{tabular}{|c|c|c|c|c|c|c|c|}
\hline Level & $\begin{array}{l}\text { Concentration } \\
\text { Moless }\end{array}$ & Fmole/hr & Kmole/hr & 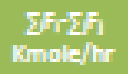 & $\underset{K \text { Kmole/hr }}{F_{c}}$ & Amole/hr & $\begin{array}{l}\text { Cum Am } \\
\text { Kmole/h }\end{array}$ \\
\hline 1 & 0.01 & 0.0 & 0.0 & 0.0 & $\begin{array}{c}F_{k}=2257.9641 \\
2257.9641\end{array}$ & & 0.0 \\
\hline 2 & 0.1 & 1011.19 & 3276.9 & -2265.71 & -7.7459 & 0.2032 & 0.2032 \\
\hline 3 & 4.38 & 2024.99 & 2024.99 & 0.0 & -7.7459 & -0.0332 & 0.1701 \\
\hline 4 & 9.78 & 0.0 & 376.85 & -376.86 & -384.6059 & -0.04183 & 0.1282 \\
\hline 5 & 9.814 & 2141.20 & 0.0 & 2141.20 & 1756.5941 & -0.0131 & 0.1151 \\
\hline 6 & 9.836 & 0.0 & 1287.8 & -1287.8 & 468.7941 & 0.0387 & 0.1538 \\
\hline 7 & 10.79 & 22434.72 & 22434.72 & 0.0 & 468.7941 & 0.4472 & 0.6010 \\
\hline 8 & 15.77 & 0.0 & 2873.48 & -2873.48 & -2404.6859 & 2.3346 & 2.9356 \\
\hline 9 & 16.96 & 2396.94 & 0.0 & 2396.94 & -7.7459 & $\begin{array}{c}-2.8616 \\
-\end{array}$ & 0.0740 \\
\hline 10 & 26.52 & 515.15 & 0.0 & 515.15 & 507.4041 & -0.0741 & 0.000 \\
\hline 11 & 45.43 & 276.61 & 0.0 & 276.61 & 784.0141 & 9.5950 & 9.9950 \\
\hline 12 & 53.16 & 97.90 & 0.0 & 97.90 & 881.9141 & 6.0504 & 15.6950 \\
\hline 13 & 58.22 & 122.60 & 0.0 & 122.60 & $\mathrm{FD}=1004.5141$ & 4.4625 & 20.1179 \\
\hline 14 & 100 & & & & & 41.9686 & 62.0660 \\
\hline
\end{tabular}




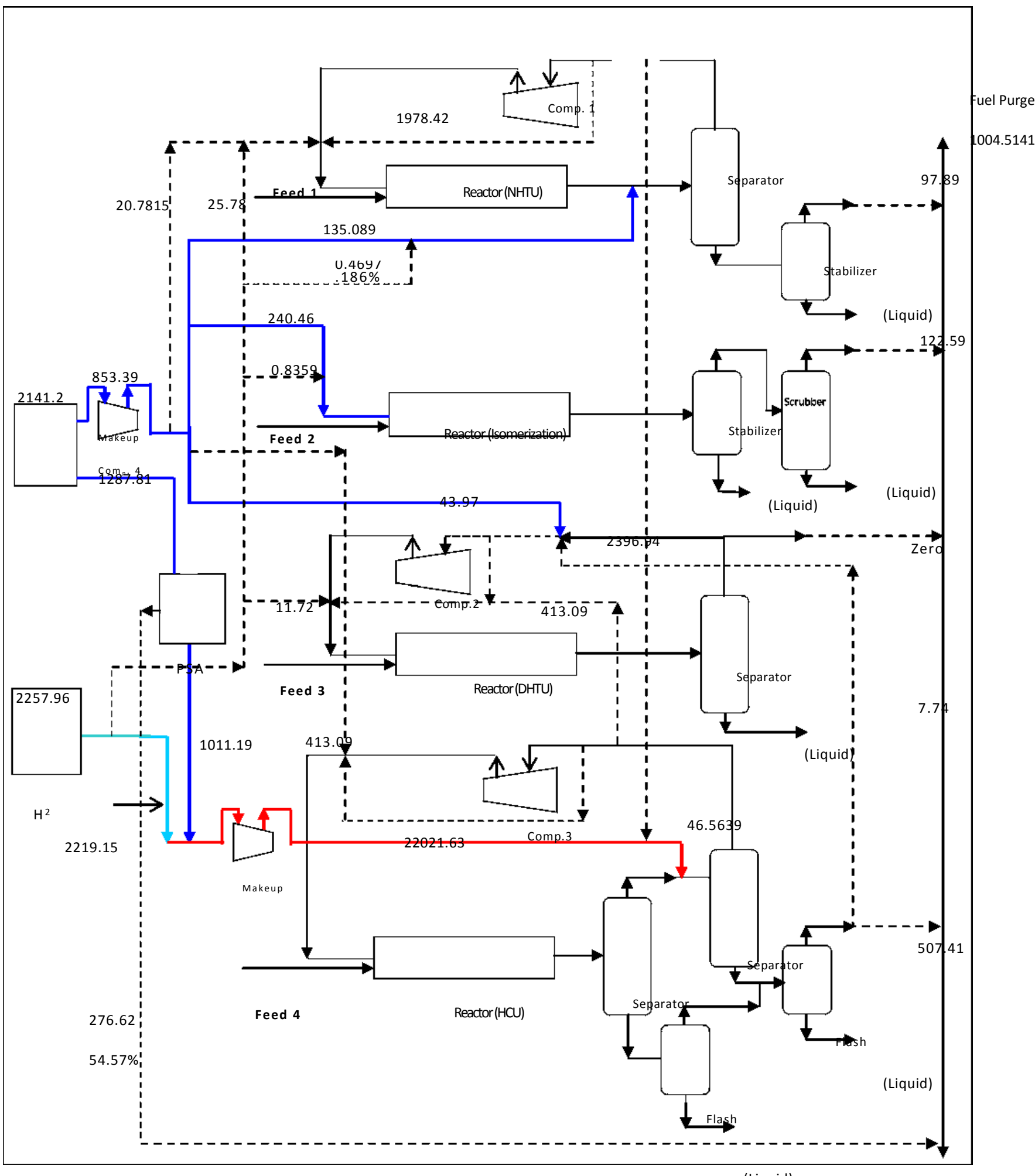

Figure 8. Hydrogen Integration Network in the Case Study by Cascade Technique. 


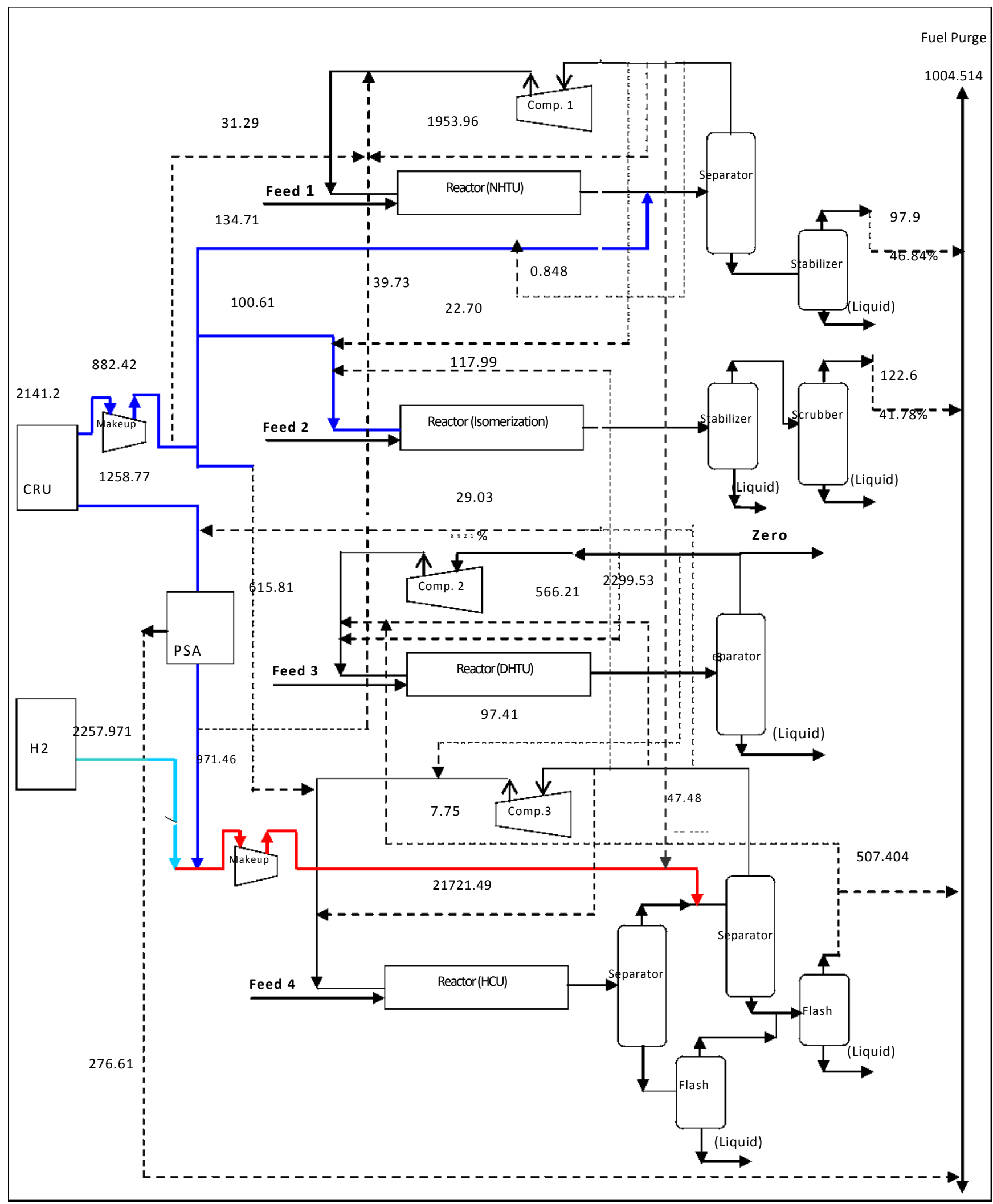

Figure 9. Hydrogen Integration Network in the Case Study by Mathematical Technique. 
Table 5: Cascade Table for the hydrogen network in the case study (Regeneration with Membrane).

\begin{tabular}{|c|c|c|c|c|c|c|c|}
\hline Level & $\begin{array}{c}\text { Concentration } \\
\text { Moles: }\end{array}$ & Kenole/hr & Fonolefitr & $\sum_{\text {Kmole/hr }}^{\sum F_{i}-I_{1}}$ & $\begin{array}{c}F_{c} \\
\text { Kmole/hr }\end{array}$ & $\underset{\text { Kmole/hr }}{\Delta \mathrm{m}}$ & $\begin{array}{l}\text { Cum Am } \\
\text { Kmole/hr }\end{array}$ \\
\hline 1 & 0.01 & 0.0 & 0.0 & $F_{;}=2163.216$ & $\begin{array}{c}0.0 \\
2163.216\end{array}$ & & 0.0 \\
\hline 2 & 0.1 & 1011.19 & 3276.9 & -2265.71 & -102.4940 & 0.1947 & 0.1947 \\
\hline 3 & 2 & 808.61 & 0.0 & 808.61 & 706.1160 & -0.1947 & 0.000 \\
\hline 4 & 4.38 & 2024.99 & 2024.99 & 0.0 & 706.1160 & 1.6906 & 1.6806 \\
\hline 5 & 9.78 & 0.0 & 376.86 & -376.86 & 329.2560 & 3.8130 & 5.4936 \\
\hline 6 & 9.814 & 2141.2 & 0.0 & 2141.2 & 2470.4560 & 0.0112 & 5.5048 \\
\hline 7 & 9.836 & 0.0 & 1287.8 & -1287.8 & 1182.6560 & 0.0544 & 5.5592 \\
\hline 8 & 10.79 & 22434.72 & 22434.72 & 0.0 & 1182.6560 & 1.1283 & 6.6875 \\
\hline 9 & & 0.0 & 2873.48 & & -1690.8240 & $\begin{array}{c}5.8896 \\
-\end{array}$ & 12.5771 \\
\hline 10 & 16.96 & 1392.43 & 0.0 & 1392.42 & -298.4040 & -2.0121 & 10.5650 \\
\hline 11 & 26.52 & 515.15 & 0.0 & 515.15 & 216.7460 & 2.8527 & 13.4177 \\
\hline 12 & 45.43 & 276.61 & 0.0 & 276.61 & 493.3560 & 4.0887 & 17.5164 \\
\hline 13 & 53.16 & 97.9 & 0.0 & 97.9 & 591.2650 & 3.8136 & 21.3300 \\
\hline 14 & 58.22 & 122.6 & 0.0 & 122.6 & 713.8560 & 2.9918 & 24.3218 \\
\hline 15 & 78.71 & 195.9 & 0.0 & 195.9 & $\mathrm{FD}=909.7560$ & 14.6269 & 38.9487 \\
\hline 16 & 100 & & & & & 19.3687 & 58.3174 \\
\hline
\end{tabular}


Table 6: Cascade Table for the hydrogen network in the case study (Regeneration with PSA).

\begin{tabular}{|c|c|c|c|c|c|c|c|}
\hline Level & $\begin{array}{c}\text { Concentration } \\
\text { Malefs }\end{array}$ & Kmole/hr & Kmolefitr & 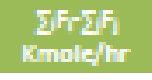 & $\begin{array}{c}F_{e} \\
K m o l e / h r\end{array}$ & $\begin{array}{c}\Delta \mathrm{m} \\
\mathrm{Kmole} / \mathrm{hr}\end{array}$ & $\begin{array}{l}\text { Cum Am } \\
\text { Kmole/hr }\end{array}$ \\
\hline 1 & 0.01 & 0.0 & 0.0 & $F_{b}=1926.35$ & $\begin{array}{c}0.0 \\
1926.35\end{array}$ & & 0.0 \\
\hline 2 & 0.1 & 1762.68 & 3276.9 & -1514.22 & 412.13 & 0.1737 & 0.1737 \\
\hline 3 & 4.38 & 2024.99 & 2024.99 & 0.0 & 412.13 & 1.7639 & 1.9376 \\
\hline 4 & 9.78 & 0.0 & 376.86 & -376.86 & 35.27 & 2.2255 & 4.1631 \\
\hline 5 & 9.814 & 2141.2 & 0.0 & 2141.2 & 2176.47 & 0.0012 & 4.1643 \\
\hline 6 & 9.836 & 0.0 & 1287.8 & -1287.8 & 888.67 & 0.0479 & 4.2122 \\
\hline 7 & 10.79 & 22434.72 & 22434.72 & 0.0 & 888.67 & 0.8478 & 5.0600 \\
\hline 8 & 15.77 & 0.0 & 2873.48 & -2873.48 & -1984.81 & 4.4256 & 9.4856 \\
\hline 9 & 16.96 & 1392.43 & 0.0 & 1392.43 & -592.38 & $\begin{array}{c}-2.3619 \\
-\end{array}$ & 7.1237 \\
\hline 10 & 26.52 & 515.15 & 0.0 & 515.15 & -77.23 & -5.6632 & 1.4605 \\
\hline 11 & 45.43 & 276.61 & 0.0 & 276.61 & 199.38 & -1.4605 & 0.000 \\
\hline 12 & 53.16 & 97.9 & 0.0 & 97.9 & 297.28 & 1.5412 & 1.9412 \\
\hline 13 & 58.22 & 122.6 & 0.0 & 122.6 & 419.88 & 1.5042 & 3.0454 \\
\hline 14 & 67.03 & 253.03 & 0.0 & 253.03 & $F D=672.91$ & 3.6991 & 6.7445 \\
\hline 15 & 100 & & & & & 22.1858 & 28.9303 \\
\hline
\end{tabular}




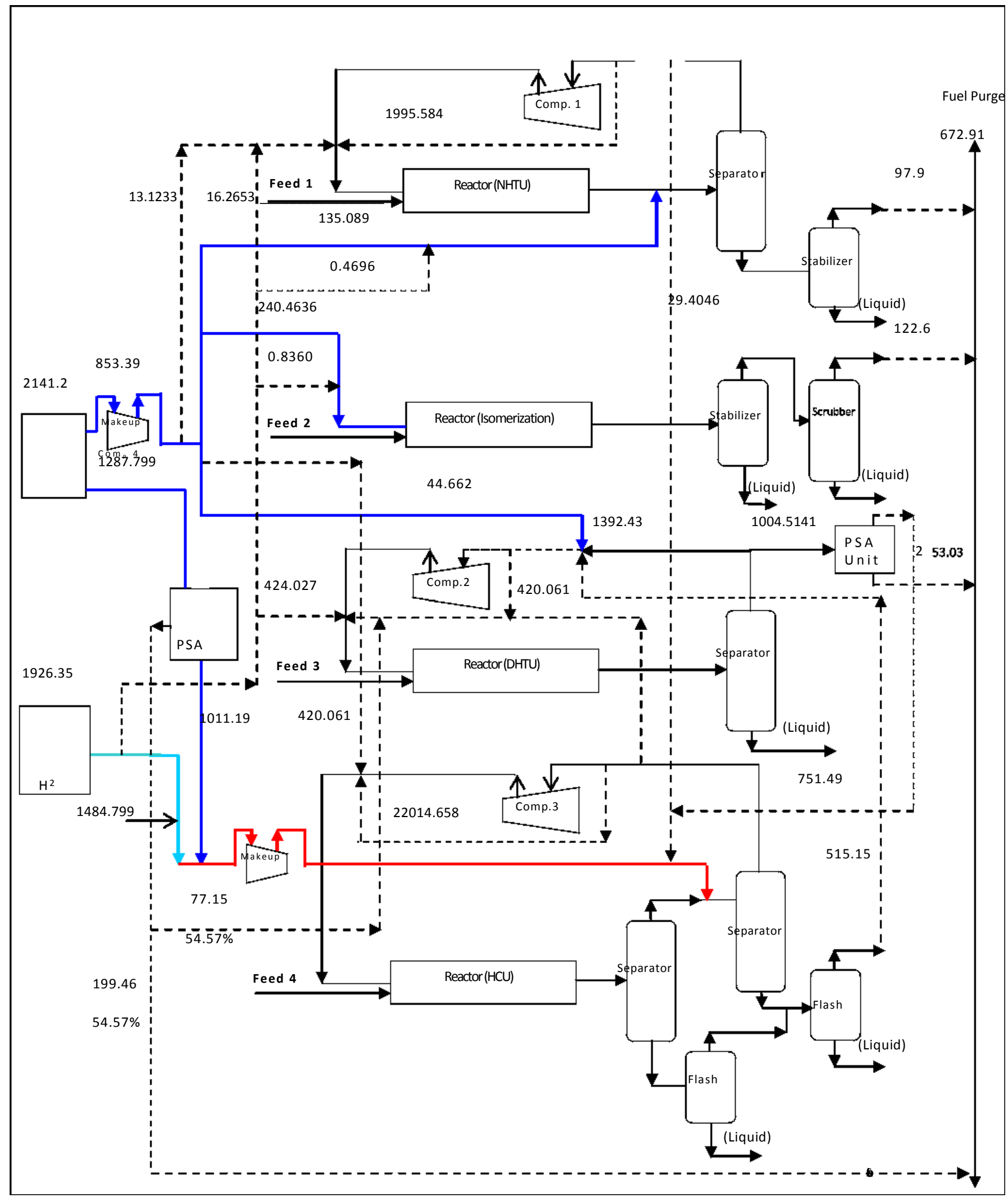

Figure 10. Hydrogen Integration Network with adding a PSA Unit by Cascade Technique. 


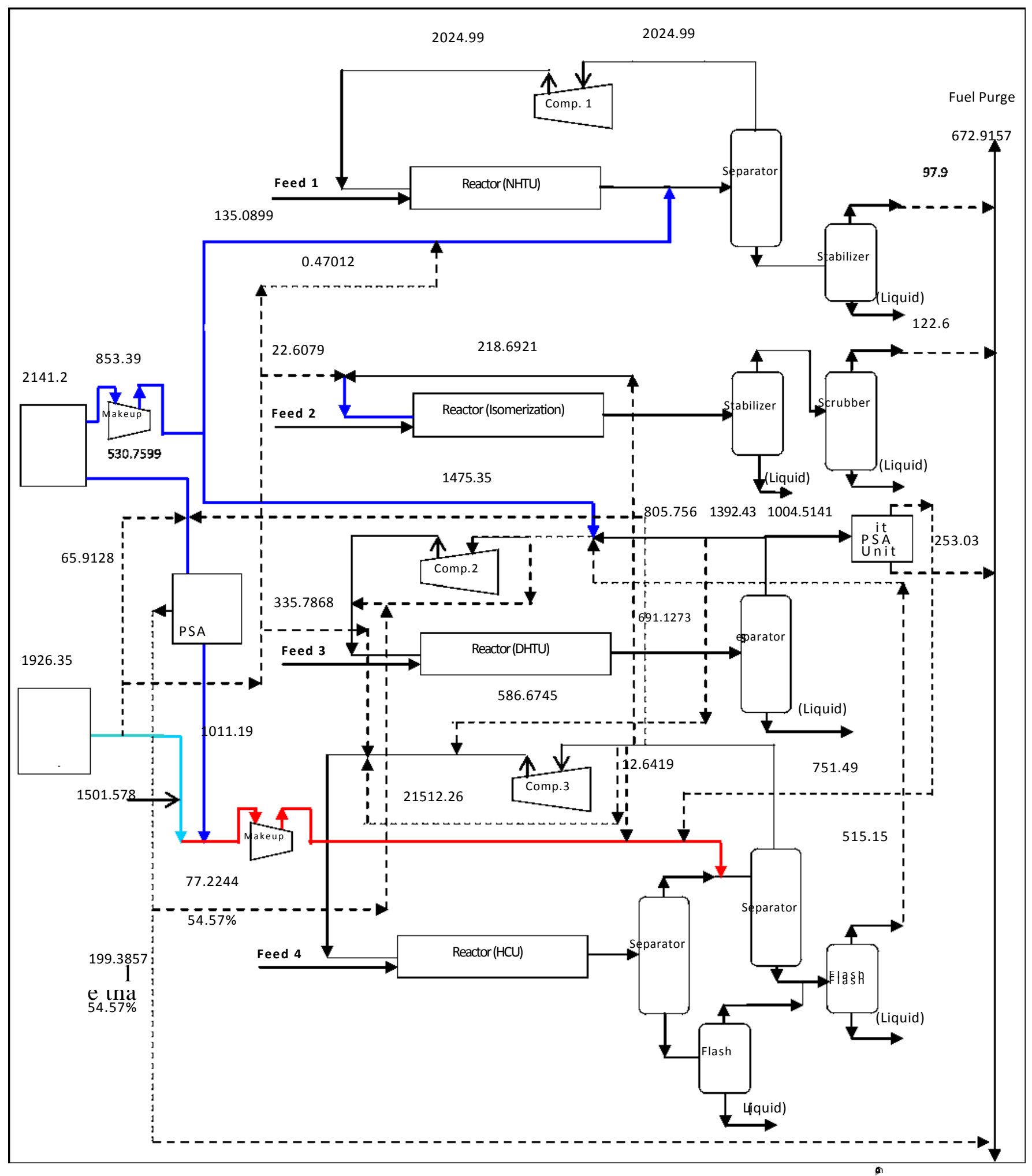

Figure 11. Hydrogen Integration Network with adding a PSA Unit by Mathematical Technique. 
Table 7: Cost Calculation Results.

\begin{tabular}{|c|c|c|c|c|}
\hline Items & $\begin{array}{c}\text { Existing } \\
\text { Network } \\
\text { Cost } \\
\text { (MUS\$/yr) }\end{array}$ & $\begin{array}{c}\text { Network } \\
\text { integration } \\
\text { Cost } \\
\text { without } \\
\text { adding any } \\
\text { equipments }\end{array}$ & $\begin{array}{l}\text { Network } \\
\text { integration } \\
\text { Cost with } \\
\text { adding a } \\
\text { membrane } \\
\text { (MUS\$/yr) }\end{array}$ & $\begin{array}{l}\text { Network } \\
\text { integration } \\
\text { Cost with } \\
\text { adding a } \\
\text { PSA } \\
\text { (MUS\$/yr) }\end{array}$ \\
\hline $\begin{array}{l}\text { Hydrogen } \\
\text { Cost }\end{array}$ & 33.336 & MUS\$ $/ y$ & 31.86 & 28.369 \\
\hline $\begin{array}{c}\text { Power } \\
\text { Cost }\end{array}$ & 2.166 & 2.166 & 2.166 & 2.166 \\
\hline Fuel Cost & -9.570 & -9.510 & -9.340 & -7.845 \\
\hline $\begin{array}{c}\text { Total } \\
\text { Operating } \\
\text { Cost }\end{array}$ & 25.932 & 25.906 & 24.686 & 22.69 \\
\hline $\begin{array}{c}\text { Operating } \\
\text { Cost } \\
\text { saving }\end{array}$ & Base & 0.026 & 1.246 & 3.242 \\
\hline $\begin{array}{c}\text { Capital } \\
\text { Cost }\end{array}$ & - & - & - & 7.51 MUS\$ \\
\hline $\begin{array}{l}\text { Payback } \\
\text { period }\end{array}$ & - & - & - & 2.316 year \\
\hline $\begin{array}{l}\text { Total } \\
\text { Annual } \\
\text { Cost }\end{array}$ & - & - & - & $\begin{array}{c}24.49 \\
\text { MUS\$/yr }\end{array}$ \\
\hline
\end{tabular}

\section{Conclusion}

The two techniques, cascade and mathematical technique gave results very near to each other.

$\square$ In the integration of Medor hydrogen network without adding any new units and applying the cascade technique or the mathematical technique, it is found that, the saving in the fresh hydrogen is $0.25 \%$ and the saving in the hydrogen discharge is $0.77 \%$.

$\square$ When adding a membrane as a purification unit and applying the cascade technique or mathematical technique, it is found that, the saving in the fresh hydrogen is $4.44 \%$ and the saving in the hydrogen discharge is $9.43 \%$.
When adding a PSA as a purification unit and applying the cascade or mathematical technique it is found that the saving in the fresh hydrogen is $14.9 \%$ and the saving in the hydrogen discharge is $33.0 \%$.

The saving in the operating cost is 3.242 MUS\$year achieved by using the PSA purifier and the saving of the operating cost is 1.246 MUS\$/year achieved by using a membrane.

\section{Nomenclature}

$\mathrm{CRU}=$ Catalytic reforming unit

$\mathrm{HCU}=$ Hydrocracking unit

DHT $=$ Diesel Hydrotreating

KHT $=$ Kerosene Hydrotreater

$\mathrm{CNHT}=$ Cracked naphtha hydrotreater

$\mathrm{NHT}=$ Naphtha hydrotreater

HDA $=$ Hydrodealkylation

Fuel $=$ Fuel gas system

PSA $=$ Pressure swing adsorption

MMSCFD $=$ Million standard cubic feet per day

FFuel $=$ Fuel flow rate

$F_{M}=$ Hydrogen make-up flow rate

$\mathrm{YM}_{\mathrm{M}}=$ Hydrogen make-up composition

$F_{R}=$ Hydrogen recycle flow rate

$Y_{R}=$ Hydrogen recycle composition

$\mathrm{FP}=$ Hydrogen purge flow rate

$\mathrm{YP}=$ Hydrogen purge composition

$\mathrm{FD}=$ Discharge hydrogen flow rate

$\mathrm{FF}=$ Fresh Hydrogen flow rate

$\mathrm{C}_{\mathrm{k}}=$ Concentration level

$\mathrm{C}_{\mathrm{F}}=$ Concentration of fresh hydrogen

$\mathrm{F}_{\mathrm{i} \text {,pur }}=$ Flow rate of purifier

Fprod, $\mathrm{j}=$ Flow rate of product stream of the purifier

Fresidual $=$ Flow rate of residual stream of the

purifier

Yprod $=$ Purity of product stream of the purifier

$\mathrm{R}=$ Hydrogen recovery of the purifier

$\mathrm{i}, \mathrm{j}=$ From source $\mathrm{i}$ to sink $\mathrm{j}$

$\mathrm{wi}=$ Flow rate of source stream

$w_{i, j}=$ Flow rate from source $i$ to sink $j$ 
$\mathrm{F}_{\mathrm{j}}=$ Flow rate of fresh hydrogen to sink $\mathrm{j}$

$\mathrm{Zj}=$ Composition of sink $\mathrm{j}$ after mixing of sources fractions and fresh fractions

$\mathrm{N}_{\text {sources }}=$ Total number of source streams

$\mathrm{N}_{\text {sinks }}=$ Total number of sink streams

$\mathrm{G}_{\mathrm{j}}=$ Flow rate of sink $\mathrm{j}$ after mixing of sources fractions and fresh fractions

$\mathrm{W}_{\mathrm{i} \text {, waste }}=$ Flow rate from source $\mathrm{i}$ to waste

$\mathrm{T}_{\mathrm{AC}}=$ Total annual cost

CappsA $=$ Capital cost of PSA

Af $=$ Annualizing factor

$\mathrm{f}_{\mathrm{i}}=$ the fractional interest

ny $=$ number of the years

$\mathrm{LHV}=$ Lower heating value

MUS\$ = Million American dollar

$F_{\text {in }}=$ inlet flow rate to purifier

$\mathrm{P}_{\mathrm{wr}}=$ Compressor power

Comp. $=$ Compressor

\section{Reference}

[1] Hallale, N. and Liu, F., "Refinery Hydrogen Management for Clean Fuels Production", Advances in Environmental Research 2001, 6, 8198.

[2] Phillips, G., "Hydrogen Innovative Business Solutions for 2005 \& Beyond", the European Refining Technology Conference-Process, Paris, France, November 1999.

[3] Peramanu, S., Cox, B.G., and Pruden, B.B., "Economics of hydrogen recovery processes for the purification of hydroprocessor purge and off-gases", International Journal of Hydrogen Energy 1999, 24, 405-424.

[4] Linnhoff, B., Townsend, D. W. and Boland, D.,"User Guide on Process Integration for the Efficient use of Energy", IChemE, Rugby, UK, 1982.

[5] Aitani, A. M., "Processes To Enhance Refinery-Hydrogen Production", Journal of Hydrogen Energy 1995, 21(4), 267-271.
[6] Alves, J.J., "Analysis and design of refinery hydrogen distribution system", PhD Thesis, Department of Process Integration, UMIST, U.K, Manchester, 1999.

[7] Ahmad, M.I., Jobson, M., and Zhang, N., "Multi-period hydrogen management", Chemical Engineering Transactions 2009, 18, 743-748.

[8] Hallale, N., "A New Graphical Targeting Method for Water Minimization", Advances in Environmental Research July 2002, 377-390.

[9] Simpson, D.M., "Hydrogen management in a synthetic crude refinery", International Journal of Hydrogen Energy 1984, 9, 95-99.

[10] Towler, G.P., Mann, R., Serriere, A.J., and Gabaude, C.M.D., "Refinery hydrogen management: cost analysis of chemically integrated facilities", Industrial and Engineering Chemistry Research 1996, 35, 23782388 .

[11] Linnhoff, B., Mason, D.R., and Wardle, I., "Understanding heat exchanger networks", Computers and Chemical Engineering 1979, 3, 295.

[12] Liu, F., "Hydrogen integration in oil refineries", $\mathrm{PhD}$ Thesis, Department of process integration, UMIST, U.K., Manchester, 2002.

[13] Liu, F., and Zhang, N., "Strategy of purifier selection and integration in hydrogen networks", Chemical Engineering Research and Design 2004, 82, 1315-1330.

[14] Miller, G., and Stoecker, J., "Selection of a hydrogen separation process", In: NPRA Annual Meeting, San Francisco, CA; 1989. 
[15] Liao, Z, Wang, J, Yang, Y, and Rong, G, "Integrating purifiers in refinery hydrogen networks: a retrofit case study", Journal of Cleaner Production 2010, 18, 233-241.

[16] Foo, D. C. Y., and Manan, Z. A., "Setting the Minimum Utility Gas Flow rate Targets Using Cascade Analysis Technique”, Ind. Eng. Chem. 2006, 45, 5986-599.

[17] El-Halwagi, M. M., "Pollution Prevention through process Integration", Systematic Design Tools; Academic Press: San Diego,CA, 1997.

[18] El-Halwagi, M. M.; Gabriel, F.; Harell, D., "Rigorous Graphical Targeting for Resource Conservation via Material Recycle/Reuse Networks", Ind. Eng. Chem. Res. 2003, 42, 4319-4328.

[19] Aly, S., Abeer, S., and Awad, M., "A new systematic approach for water network design", Clean Technologies Environmental Policy 2005, 7 (3), 154- 161.

[20] Elkamel, A., Alhajri, I., Almansoori, A. and Saif, Y., "Integration of hydrogen management in refinery planning with rigorous process models and product quality specifications", Int. J. Process Systems Engineering 2011, 1,302330.

[21] Ratan, S., "Hydrogen Management Systems", KTI Newsletter, Fall, 1994, 24-32. 